\title{
Talk and Texts at Work: Beyond language and literacy skills
}

\author{
HERMINE SCHEERES
}

\begin{abstract}
In this paper I discuss changing work practices in post-bureaucratic organisations (Heckscher and Donellon 1994, Iedema 2003) as a move from a focus on how those in control formulate what is to happen at the level of work, towards requiring workers to verbalise how they see themselves as being able to contribute to the organisation. Workers are increasingly asked to talk about their work, and to negotiate their understandings of their work with others in the workplace - they are becoming discourse workers. This discourse work is integral to the increasing textualisation of work. These work practices are imbued with tensions as workers try to make sense of, and learn, new ways of 'being' a worker, and an important site of this struggle and learning is working in teams.

The article begins with a brief outline of some key aspects of the changing workplace and changing worker. It goes on to present these organisational shifts in terms of worker identities and suggests that workers are engaged in identity-work and the increasing textualisation of the workplace. I draw on theorisations of identity and the production of the subject (Gergen 1991, Hall 1996, Rose 1996, 1999) to provide a frame to explore textualisation (Belfiore, Defoe, Folinsbee, Hunter and Jackson 2004, Iedema and Scheeres 2003, Jackson 2000). The paper then turns to a presentation of empirical data from case study research on teams in a large manufacturing company in Sydney, Australia, to demonstrate that workers are struggling with who to 'be' as their work shifts from manual labour or 'doing' work, to include social labour or talk as constitutive of work. The workers that I focus on are, in the main, production-line workers, together with the facilitators and trainers who are charged with producing the linguistically competent workers that organisations desire. The paper concludes with some implications for workplace learning, and for language and literacy programs and practitioners.
\end{abstract}

\section{Introduction: Changing work, changing workers}

In the contemporary workplace, management structures are changing to allow for a flatter hierarchy leading to new roles and responsibilities for all employees. Traditionally, the onus has been on managers and 
supervisors to spell out what is to happen and to do this they have deployed different kinds of commands. Now there is an increasing expectation that workers will not only make statements describing their work, but that they will discuss how they will do their work in the future and who they will be as workers. These changes are interpreted by some as signalling an improvement in work conditions on the strength of enhanced kinds of participation and 'say' (eg Adler, 2001). For commentators like Gee, Hull and Lankshear, (1996), du Gay (1996) and others, the calls for worker involvement and self-expression are generally rejected as managerialist ploys seeking to engender 'entrepreneurialism' and 'responsibilisation' on the part of workers. Notwithstanding this binary, there is a growing expectation that employees not only talk and write about their work in new ways, but they are positioned so that they offer ways of taking their work further. What we are seeing in today's organisations is a determined move to foreground social relationships amongst employees and to draw on their knowledge and experience no matter what their occupational level.

\section{(Re)Inventing organisational selves}

A focus on work practices in terms of social relations and knowledge work, leads to an exploration of the implications for managers and employees in terms of identity (Rhodes, Iedema and Scheeres 2007 in press; Caldas-Coulthard and Iedema 2007 in press; Farrell 1999; Scheeres and Solomon 2006; du Gay 1996; Hall and du Gay 1996; Gee, Hull and Lankshear 1996). What is now expected, indeed what is essential to being a competent worker, is not only an awareness of and ability to 'invent our selves' (Rose 1996) but the capacity to re-invent ourselves as different kinds of 'organisational selves' throughout our working lives. Gergen (1991) characterises this as the postmodern condition where:

persons exist in a state of continuous construction and reconstruction; it is a world where anything goes that can be negotiated. Each reality of self gives way to reflexive questionings, irony, and ultimately the playful probing of yet another reality. (p 5-6)

In their discussion of the growing prevalence of portfolio workers (Handy 1995, Fenwick 2004), Grey and Garsten (2001) think beyond the development of new identities in their proposal that the 'flexibilisation of working practices and organizational forms are matched by attempts to flexibilise the self' (240). For employees and managers, especially those who have been in the workforce for some time, work on the self and reflexivity are new but persistent experiences in this new world of working (on) identities. This work involves building continuous learning into jobs and 
into organizations (Marsick and Watkins 1999, Senge 1990). Alongside the variety of formal and informal ways of learning, the textualising workplace involves workers learning about all parts of the organisation in order not only to 'own' the goals and practices but also to be able continually to recognise problems and offer innovative solutions.

\section{Textualisation of work and the workplace}

The shift to a textualised workplace has implications for what work is and how to learn to be a worker. It is not just that there are new communication demands that workers may or may not be competent in, but the workplace itself is increasingly one that is a site of textual practices that affect everyone in some way. Workplaces are becoming increasingly textualised through the introduction of technological hardware and software; through increased inhouse continuous, education and training; through making explicit to workers at all levels how the organisation functions by posting production reports and the like; through participatory practices such as teams for everything; through complex quality and accountability processes; and through a myriad of other textual processes and products. Knowledge in workplaces is expected to be discursively constructed knowledge in meeting rooms, around walls, on computer screens, in manuals, and so on.

The notion of textualisation of work has been discussed by Jackson (2000) and others in their research on the intensification of literacy demands in industrial workplaces. However, other texts are produced and displayed in the workplace as both new kinds of texts and in new contexts. So, for example, at Arturo ${ }^{1}$, the workplace I focus on in this paper, the new space, the meeting room, is a location that every worker is now familiar with, its walls lined with texts related to work, workers and the workplace in a range of ways. Similarly, around the walls of the factory floor, graphs, diagrams, spreadsheets of faults, production numbers, pictures of teams and team members, texts that were non-existent five or ten years ago, and texts that would only have filled managers' in and out trays, now form part of what it is to be a new order workplace. Together all of these represent the textualisation of the workplace, a workplace where a proliferation of texts in public spaces is part of the identification of a 'normal' industrial workplace.

There has been considerable research and pedagogical work in relation to workplaces and workers that has focused on some of the kinds of texts mentioned above. There has been work on the literacy demands of new work, on language skills, especially for language background other than English (LBOTE) workers, and on broader areas of communication such as negotiation and conflict resolution and the like. Notwithstanding this valuable work, I want to propose a somewhat different perspective. Underpinning this perspective is an understanding of Arturo as a workplace 
where the relationships between the doing work of the production-line and the discursive work of the meeting room are not only about moving from one physical space to another, and from making things to talking and writing about making things. The relationships amongst employees are also redesigned as the workplace itself becomes a site where interactions are salient. The workplace is at one and the same time a textualised workplace, where produced texts and talk proliferate, and a textualising workplace where the production of texts and talk has become everyday work.

Hence, I want to suggest a broad interpretation of textualisation of the workplace that a colleague, Rick Iedema and myself have been developing and working with. For us:

the textualisation of work is about people ... 'discoursing' across what used to be hierarchical, occupational, professional or organisational boundaries. Workers are called on, or volunteer, to engage in ways of speaking (and writing), that call into question conventional conceptions of what it means to be and speak like ... a line operator, or a shop floor supervisor. These people are expected to embody not only the discourses that they were conventionally inducted into as workers, or those that have been functional in supporting their work. ( ....) Increasingly, workers from all backgrounds are confronted with kinds of workplace reform and restructuring that put cross-professional and cross-occupational negotiation centre-stage. (Iedema and Scheeres 2003)

More and more work is talk, and the discursive practices that constitute this talk provide a means for workers to engage in interactions about their work to others with whom they would not normally negotiate the details of what they do. The focus for us, then, has come to be on textualisation as processes of networking and aligning, of developing new social relations implicating changing identities. The social relations are not static, they are characterised as potentially always on the move and therefore the ways of being are dynamic and contested positions or identities.

The discussion now turns to the research site, Arturo, an Australian workplace where ongoing restructuring and reorganisation are taking place. This manufacturing workplace is one where texts and talk are producing new work practices and new worker identities. The research project reported on here involved ethnographic methods of observation and semistructured interviews plus analyses of a variety of company documents. A major part of the research involved the taping, transcribing and discourse 
analysis of team meetings. The focus of discussion in this paper is team meeting interactions and the textualising and identity work they enact.

\section{The research site}

Arturo's continued existence is dependent on maintaining or, more importantly, improving its competitive position in the national and international marketplace. The non-unionised site in an industrial suburb of Sydney, Australia, employs approximately 800 workers, the majority of whom are from language backgrounds other than English. Most of these workers are deployed on production lines manufacturing gaming machines. A shared vision is being created and built up in the organisation wherein all workers must understand the big picture and the company goals, and become informed of, and intimately involved in, current productivity targets and levels. In answering the expectation that they show awareness and knowledge of these goals, workers are spending increasing amounts of time on discourse work.

A unit comprising a manager and five facilitators has been created in the company to organise and develop teams. The five facilitators chosen to head these teams had been leading hands on the 'old' workplace factory floor. One of the facilitators, Carol, began work in the factory as a process worker soldering components four years earlier. She had been a leading hand for some time before becoming a facilitator in this new unit. As a leading hand, she was still located on the factory floor and still engaged in some process work. As a facilitator, by contrast, Carol has shifted from doing the work of the production line to textualising work that is more discourse-focused.

Carol is responsible for organising teams in the main manufacturing plant of the company. She recognises that her work is involved with the formidable process of 'changing workplace culture' (Interview: Carol, Team Facilitator). She explains how she goes about trying to accomplish this cultural change using 'tools and techniques' including 'Problem Solving Plus' and 'Station Control', both of which are highly structured, step-by-step procedures designed to lead to predictable production improvements.

\section{Working in teams}

The teams that have been set up to use these tools and techniques are cross-functional teams made up of between eight and 12 employees. They meet for one hour every week either at the beginning or end of a shift. Each member of a particular team works in a different area of the manufacturing process, and the team may include people from different hierarchical levels of the workplace. The key focus is efficient production: improving and streamlining the 'doing' of the work. The pathway to this improved and 
more efficient 'doing' is deemed to be located within the successful 'workings' of teams.

Training for teams, that is, how to be a(n effective) team member; how to work (effectively) in a team; how to participate (effectively) in team meetings and so on, has been a focus for training at Arturo. The training is part of the textualising workplace and the training itself, as well as the focus of the training, is discursive work. Production-line workers are expected to have command over a variety of texts and talk. They have to be able to describe, explain, report on, argue, problem-solve, negotiate and generally discuss not only what is involved at their own work station but they are also expected to competently engage in talk about other parts of the production process that may or may not be closely related to their own. Central to these practices is the expectation that these team members will take the floor (Edelsky 1993), in particular through offering ideas and solutions to problems. The positioning of workers as experts or knowledge workers (Drucker 1993) who have ideas and solutions to offer, means that the ensuing social relationships they are expected to develop are in contrast to more traditional ones where they merely respond to directives. This talk (and it is predominantly talk) usually occurs in and around the team meetings.

\section{From doing work to talk and texts}

As the data presented below aim to illustrate, this engagement is evident in the discursive strategies that team members enact in front of one another. The interactions discussed here involve production-line operators and Carol, the team facilitator. The team talk implicates further and related activities: there are tasks to be completed in between meetings, documents to be drafted and re-edited, and resources to be tracked down for consideration or inclusion, as well as, of course, carrying out regular production-line work.

The majority of the meetings I observed and taped, were facilitated by Carol, and were dominated by the PSP (Problem Solving Plus) procedures. Meetings often opened with Carol prompting reflection on the last meeting together with an outline of a clear direction and task(s) for that day's meeting. Tools and techniques like PSP provide a procedure and a structure for meetings, but they are also important in standardising an approach to finding and fixing problems. Developing and learning a documented, common and collaborative approach is understood as a way of being pro-active, of minimising reactive and crisis behaviours, and as a way of standardising future procedures. 


\section{Team meeting 1: Missing components}

In the extract below Carol plays a principal role in making the meeting 'work'. The team in this example is focusing on a particular missing component and they have spent the last two meetings talking about the 'problem' (describing, reporting and explaining) and translating the talk into a written text called a 'problem statement'. Now Carol $(\mathrm{C})$ introduces the next step, the writing of the 'target statement' (discussing and negotiating) as the current task. She encourages participation, in particular she works to elicit responses. The target statement should be composed by the workers as an outline of what they had previously agreed was a problem, then include suggested ways of 'fixing' the problem. At this meeting there are six workers/team members (TMs) present, plus their team leader (who does not speak) and the facilitator.

\section{Extract 1}

C We're going to go on with the PSP. You have the tally sheets. Now the PSP, we follow the PSP. We've written our problem statements and now we're about to write our target statements and then we're up to stage two. [5] Okay? So, what should a target statement have? It says there the target statement is a written description of the results that you expect to achieve. Yeah. We wrote last week, the week before last, what the problem is. From there what do we want to achieve, what's our goal? Okay? The target statement must be specific and the target statement describes the following. Number one, what is it that you are going to achieve? So when we look at what we want to achieve, what did we have?

TM1 [mumbles an inaudible response]

C Okay, so we're getting on average four missing components per week. Are you gonna be happy if you get three?

TM2 reah.

G $\quad$ a, is that your ultimate aim? Would you like to get three or would you like to get two or one or zero?

[Many speak at once with answers]

TM3 Zero would be the best [laughter from team members]

Carol sets the agenda, and the team members wait for and expect her to control the work of the meeting. Carol's talk consists of a series of statements about what 'we' have done and what 'we' now need to do, interspersed with questions encouraging input from the team members. In this sense, Carol's talk enacts complex social relations that are (re)negotiated here. Carol's task, then, is to produce new kinds of talk, talk that shifts interpersonally from following orders to offering knowledge, expertise and 
services. Through these kinds of elicitations she is enacting and teaching new ways of being a worker.

However, there are struggles evident here. One struggle is concerned with moving from the factory floor discourses to the meeting room discourses. The meeting opens with and foregrounds meeting room PSP procedures. This discourse is aligned with the texts on the table: tally sheets with production figures and numbers of faulty machines; copies of the previously written problem statements; and definitions and models of target statements. There is a large chart of the steps of PSP held up by Carol from time to time to reinforce the standard procedure and remind people what point 'we' are at. Carol is the one who clearly engages in the PSP talk. It is only when she moves away from 'problem statements', and 'target statements', to 'goal'(s) and achievements, and then even closer to the factory floor with the concrete 'missing components' that others join in the talk. In her attempt to involve the others, Carol moves from the reflective language about this work ('problem statements', 'target statements') to language closer to the process work and the language accompanying the actions of day to day process work.

Another struggle around social relationships is played out in this team meeting and others like it. One reading of the excerpt above could be that Carol dominates the meeting. This is evidenced by her talk-time, her statements and her questions aimed at getting people to learn and participate in the meeting-work. The general knowledge that Carol now has the title 'facilitator', a non-factory floor position, may contribute to the view that she is the one who has a position of power here. However, there are complexities silenced by such a reading. Carol's shifts from 'we' to 'you' throughout the excerpt, and then using only 'you' once some kind of response is forthcoming from her 'audience,' demonstrates shifts in roles and relationships. The 'we' used in the meeting room draws the process workers into this new work as new kinds of workers - ones who, for example, devise and write problem statements and target statements. Carol's pedagogic self is moving these employees from the comfort zones of their production-line selves to the more uncomfortable team meeting selves.

\section{Team meeting 2: Incorrect light towers}

The second team meeting discussed here presents a different team and a different quality problem to solve. This team is concerned with the number of machines that proceed along the production-line with incorrect light towers. Each type of gaming machine has a specific configuration of flashing lights called a light tower, but there is an ongoing problem matching the right light tower with its particular type of machine. 
In this extract Carol $(\mathrm{C})$ again takes the first long turn to begin the discussion with six team members, only two of whom speak during this extract (TM 1-2). This team is further advanced in their project than is the team in team meeting 1 . They have written out problem statements and target statements; they have visited the light tower assembly part of the production-line; and they have presented some of their research findings in written and diagrammatic forms. Notably Carol has done much of the written work translating comments from members of the team into written texts on the whiteboard and then on appropriate forms. They are now talking about possible ways of implementing solutions

\section{Extract 2}

C I need light towers now. Now I need to find out what kind of light towers. Yeah? Then they can start thinking what parts do they need for those light towers, where do those parts come from for those light towers. Start ordering. Yeah? What we'll do is we'll set off like a, er, checklist of reminders or whatever for the person making the light towers. Then we still need to look at, well if she hasn't got the parts for the light tower... fill out an NCI [non-compliance] tag. Make sure NCI tags are available there. Make sure she knows how to fill out an NCI tag and understands how to use them. [2] Mmm?

TM1 rep.

TM2 Ah another thing er in this part in comments

C LMmm.

TM2 What about if they put one more thing [inaudible] no? They put er er every light tower what part number? If they put maybe we need er 40 part number that's it?

C That's it.

TM2 So we put for example light tower the number

C LTeah.

TM2 Don't need to write everything about what kind of part [inaudible two or three words] the part number and the quantity.

C Lreah yeah yeah yeah

TM2 That's it?

G reah.

TM1 LYeah.

TM2 Singapore is coming 120. Okay I need 80 part number of this ah 40 of this.

TM1 Yeah.

TM2 And that's it?

TM1 Yeah.

C $\mathrm{Mmm}$.

TM1 Yeah. 


\section{TM2 And that's it. It is difficult for me to say [ = write in words] that \\ G Section four comments. Yes comments. \\ TM2 I've got the number that's it.}

Carol's introductory turn again sets the agenda. She outlines what the team has already achieved and what work is next for the team. The extract focuses on developing a written checklist for the operators working on assembling the light towers, so that there is more chance of the right ones being attached to the right machines. The second task Carol mentions will be to make sure the NCI (non-compliance) tags that need to be attached to the machine when a fault or missing component is detected, are available, understood and easy to fill in.

Following Carol's turn, two of the team members immediately take up speaking positions agreeing with Carol (TM1) and offering suggestions (TM2). Apart from the opening turn, Carol does not dominate the talk here. Even though the exchanges in the rest of the extract are short ones, it seems that TM2, through his offers and requests for confirmation, has taken on the problem-solving work of meetings, whilst TM1 interacts with one-word affirmative statements that represent his involvement and possibly his support.

As in team meeting 1 above, at this team meeting there are statements and questions, but now it is not only Carol who asks the questions, and it is not only these team members/production-line workers who are positioned as the doers back on the factory floor. Statements in this example begin with Carol using 'I' as someone on the production-line needing a particular part, thereby perhaps signifying solidarity with the workers, well as reconstructing the context of production. She then moves to the here-and-now work of the meeting room where 'we' are going to produce a checklist to be used in the action-at-a-distance on the productionline by others referred to as 'they' and 'she', the workers who assemble the light towers. These shifts are indicative of the different working identities Carol and the team members are embodying. For Carol, 'we' are discourse workers who are doing textualising work. Later in the extract TM2 demonstrates that he is part of this 'we' when he says, 'so we put for example light tower the number'. He is involved in talk and texts that are constructing a standardising procedure to be followed by other workers.

TM2 immediately gets down to the business of suggesting what should go in the checklist to be filled in by the light tower assemblers. He is the only one who offers and suggests during this interaction, as he demonstrates his knowledge and expertise around what happens on the factory floor. Most of his comments are tagged by the question 'that's it?' as he seeks confirmation from Carol and perhaps from fellow workers. Then, 
in his final two turns he uses the same words but as statements rather than questions. He positions himself as more assured with 'I've got the number that's it'. At the same time he is struggling with writing this up in 'section four comments'.

What is particularly notable here is that the textualising work of the meeting room consists of at least two layers. Firstly, the PSP procedures are talked about and forms are being filled in, for example, TM2 has the final form outlining implementation in front of him and is struggling with 'in this part, in comments'. Secondly, what is being talked about and then written is a checklist that should become an integral 'component' of the productionline as operators will be required to write or fill in sections, for example, 'they put er, er, every light tower what part number ...'. Thus the new meeting room work is creating new production-line work and both are part of the textualisation of work and of the workplace.

The work of teams discussed through the data extracts from team meetings show some of the struggles and positionings going on for workers in their daily work. The discussion focuses on micro-level interactions among production-line workers/team members. The identity-work that is going on in these team meetings is influenced by how teams are understood and viewed by the organisation - its managers and other employees. The history of teams and team meetings at Arturo has spanned 6 years so far and a key aspect is the organisation's commitment to teams and the work of teams.

\section{Effective teams}

Autonomy, self-management and empowerment are the discourses of the facilitators and their manager. The principal path towards greater selfmanagement by teams is, for Adrian, one of the team facilitators, education, - a kind of expertisation of the ordinary worker through knowledging. His expressed belief in the role of training is foregrounded when he states that 'they need to ... acquire the knowledge and skills that are required ... that's probably the main thing (Interview Data: Adrian, Team Facilitator). His manager, Adam, states:

But a lot of the team discussion... depending on who's leading, and Carol has a certain outcome which she would like to achieve, so she's going to point the team within that direction. (Interview Data: Adam, Manager)

For this manager, autonomy and authority are based on a bottom-up process, that is, one in which the teams themselves decide on and 'come in and talk about the issues that go on'. Allowing the teams to find their own direction would constitute giving them 'the authority to work as teams' and at the moment he sees them as too directed by facilitators like Carol. $\mathrm{He}$ 
takes seriously the new work order devolution of authority and breaking down of hierarchical boundaries.

\section{Implications of identity work for language $B$ literacy practitioners}

The term 'discourse register' is used by du Gay (1996) to define particular, institutionalised ways of talking at work. This concept could be applied to the discourse work that this organisation's workers are undertaking when they are, for example, making offers and suggestions during team meetings - the particular kind of talk that is expected of the team members and facilitators. However, my understanding of the textualisation of work and the workplace - the offers and suggestions, their relationship to the literacy tasks and practices of PSP, and the further relationships with the doing work beyond the meeting room, are complex in that they construct different meanings for the participants as they put at risk their 'old work' selves. The factory workers' hitherto naturalised position of little status and limited expertise is being re-formed as they take up and learn new positions (whether they are complying or resisting). These experiences involve them learning to be knowledge workers and articulating expertise as teams and team members - it is identity-work.

In this paper I have posited textualising work and the textualisation of the workplace as a useful way of understanding and deconstructing some new work order participative practices, particularly in relation to one workplace. This is an important understanding for workplace research and pedagogical practices where the new work order's participative agendas have created a proliferation of training practices and understandings of learning that seem often to be about requiring sets of new skills or learning roles and values through preordained activities and tasks. I am suggesting that textualisation of work and the workplace is primarily about social relations, and that learning the textualising work involves, notably, identitywork.

\section{Endnote}

1 Pseudonym

\section{References}

Adler, P (2001) Market, Hierarchy and Trust: The knowledge economy and the future of capitalism, Organization Science, vol 12, no 2, pp 215-234.

Belfiore, M, Defoe, T, Folinsbee, S, Hunter, J and Jackson, N (2004) Reading Work: Literacies in the new workplace, Lawrence Erlbaum Associates, New Jersey. 
Caldas-Coulthard, Carmen and Iedema, Rick (2007 in press) Identity Trouble: Critical discourse contested identities, Palgrave, Basingstoke.

Drucker, Peter (1993) Post-Capitalist Society, Harper, New York.

du Gay, Paul (1996) Consumption and Identity at Work, Sage, London.

Edelsky, Carole (1993) Who's Got the Floor? in Tannen, D, ed, Gender and Conversational Interaction, Oxford University Press, Oxford, pp 189-227.

Farrell, Lesley (1999) Reconstructing Sally: Narratives and counternarratives around work, education and workplace restructure, Literacy and Numeracy Studies, vol 9, no 1, pp 5-26.

Fenwick, Tara (2004) Learning Portfolio Work: Anchored innovation and mobile identity, Studies in Continuing Education, vol 26, no 2, pp 229-245

Gee, James Hull, Glynda and Lankshear, Colin (1996) The New Work Order: Behind the language of the new capitalism, Allen and Unwin, Sydney.

Gergen, K (1991) The Saturated Self, Basic Books, New York.

Grey, C and Garsten, C (2001) Trust Control and Post-Bureaucracy, Organization Studies, vol 22, no 2, pp 229-250.

Hall, Stuart (1996) Who Needs Identity?, in Hall, S and du Gay, P, eds, Questions of Cultural Identity, Sage, London, pp 1-17.

Hall, Stuart and du Gay, Paul, eds (1996) Questions of Cultural Identity, Sage, London.

Heckscher, C and Donnellon, A (1994) The Post-bureaucratic Organization: New perspectives on organizational change, Sage, Thousand Oaks, California.

Iedema, Rick (2003) The Discourses of Post-Bureaucratic Organization, John Benjamins, Amsterdam, Philadelphia.

Iedema, Rick and Scheeres, Hermine (2003) From Doing Work to Talking Work: Renegotiating knowing, doing, and identity, Applied Linguistics, Oxford University Press, Oxford, England, vol 24, no 3, pp 316-337.

Jackson, Nancy (2000) Writing-Up People at Work: Investigations of workplace literacy, Literacy and Numeracy Studies, vol 10, no 1 and 2, pp $5-22$.

Marsick, V and Watkins, K (1999) Facilitating Learning Organizations: Making learning count, Aldershot, Hampshire.

Rhodes, Carl, Iedema, Rick and Scheeres, Hermine (2007 in press) Identity, Surveillance and Resistance, in Pullen, A, Beech, N and Sims, D, eds, Researching Identity: Concepts and methods, Routledge, London, pp 83-99.

Rose, N (1999) Governing the Soul: The shaping of the private self, (2nd ed.) Free Association Books, London.

Rose, N (1996) Inventing Our Selves: Psychology, power, and personhood, Cambridge University Press, Cambridge, England.

Scheeres, Hermine and Solomon, Nicky (2006) The Moving Subject: Shifting work(ers) across and beyond organisational boundaries, in Billett, S, Fenwick, T and Somerville, M, eds, Work, Subjectivity and 
Learning: Understanding leaning through social life, Springer, Dordrecht, The Netherlands. pp 87-103.

Senge, P (1990) The Fifth Discipline: The art and practice of the learning organization, Doubleday/Currency, New York. 